\title{
INTEGRAL REPRESENTATIONS OF SOME FAMILIES OF OPERATOR MONOTONE FUNCTIONS
}

\author{
YOICHI UDAGAWA
}

Abstract. We obtain an integral representation of holomorphic function $P_{\alpha}(z)$ which is real on the positive part of the real axis and formed

$$
P_{\alpha}(x)=\left(\frac{x^{\alpha}+1}{2}\right)^{\frac{1}{\alpha}}(x \geqslant 0) .
$$

For this purpose we define a two variable function which is substituted for an argument $\theta$, and also find an explicit real and imaginary part of $P_{\alpha}(x+i y)$.

Mathematics subject classification (2010): 15A60, 47A64.

Keywords and phrases: Operator mean, operator monotone function, power mean, Pick function.

\section{REFERENCES}

[1] W. Donoghue, Monotone Matrix Functions and Analytic Continuation, Springer, Berlin, 1974,

[2] F. HAnsen, The fast track to Löwner's theorem, Linear Algebra Appl., 438 (2013), 4557-4571.

[3] F. Hansen, Trace functions with applications in quantum physics, J. Stat. Phys., 154 (2014), $807-$ 818.

[4] E. HeinZ, Beiträge zur Störungstheorie der Spektralzerlegung, Math. Ann., 123 (1951), 415-438.

[5] K. LöWnER, Über monotone Matrixfunktionen, Math. Z., 38 (1934), 177-216.

[6] Y. UdAGAWA, Operator monotonicity of a 2-parameter family of functions and $\exp \{f(x)\}$ related to the Stolarsky mean, Oper. Matrices., 11-2 (2017), 519-532.

[7] Y. UdAGAWA, S. WADA, T. YAMAZAKI AND M. YANAGIDA, On a family of operator means involving the power difference means, Linear Algebra Appl., 485 (2015), 124-131. 